\title{
Experimental study of rare earth element partitioning between calcite and sodium chloride solution at room temperature and pressure
}

\author{
KOTARO TOYAMA* and YASUTAKA TERAKADO \\ Graduate School of Human Development and Environment, Kobe University, Tsurukabuto 3-11, Kobe 657-8501, Japan
}

(Received November 5, 2013; Accepted July 14, 2014)

\begin{abstract}
The rare earth element (REE) partition coefficients between calcite and aqueous solution were obtained experimentally under the conditions of $\mathrm{pH}$, ionic strength and REE concentration level in the parent solution which were relatively close to those in seawater environment. Two different concentration levels of the REE dopant solutions were used in the experiments. The obtained partition coefficients for $\mathrm{Sm}$, which have relatively high values, range from 20.8 to 116 , and those for Lu, which show relatively low values, range from 10.9 to 79.1 . The mutual fractionations among REEs are relatively small. On the partition coefficient versus ionic radius diagram, the patterns show weak convex upward shape having a vague maximum in the light REE, but these curves are not likely to be parabolic as expected from the trace element partitioning studies for the phenocryst-magma pairs. Therefore, it was considered that the REE partitioning between calcite and aqueous solution is not mainly controlled by the crystal structure-ionic radius effect. As for the factors on the REE partitioning experiments, crystal growth rate, REE concentration level and dominant REE species in the solutions were examined, but any clear relationships were not found, although the REE concentration level might be operative. Because the experimental condition in the present study are relatively close to the natural ones, the REE partition coefficients obtained in the present study would be useful for examining the $\mathrm{REEs}$ abundances in natural $\mathrm{CaCO}_{3}$ materials.
\end{abstract}

Keywords: rare earth elements, lanthanide, calcite, partition coefficient, calcium carbonate

\section{INTRODUCTION}

Trace element concentrations in natural $\mathrm{CaCO}_{3}$ materials have been used as a tool to obtain information about paleoenvironment such as temperature, nutrient etc. For example, it has been pointed out that the $\mathrm{Sr} / \mathrm{Ca}$ ratios of coral skeletons can be used as paleotemperature proxy (e.g., de Villiers et al., 1994; Alibert and McCulloch, 1997; DeLong et al., 2011). The $\mathrm{Cd} / \mathrm{Ca}$ ratios in foraminifera tests are known to reflect the nutrient contents in seawater (e.g., Rickaby and Elderfield, 1999; Makou et al., 2010). It has been suggested that the $\mathrm{Ba} / \mathrm{Ca}$ ratios in foraminifera tests or corals can be used as a proxy of refractory nutrient or alkalinity in deep seawater (e.g., Lea, 1993; LaVigne et al., 2011). Thus, there may be a possibility that the rare earth element (REE) abundance data of calcium carbonate materials (e.g., coral, limestone etc.) involve some information about ancient seawater environments.

The REEs are a series of chemical elements from ${ }_{57} \mathrm{La}$ to ${ }_{71} \mathrm{Lu}$. Their ionic radius gradually decreases with increasing atomic number, though their chemical proper-

*Corresponding author (e-mail: 119d841d@stu.kobe-u.ac.jp)

Copyright $\odot 2014$ by The Geochemical Society of Japan. ties are similar. Therefore, the REEs are considered to be an useful tool for assessing the effect of ionic radius on geochemical processes (Henderson, 1984; Taylor and McLennan, 1988; Zhong and Mucci, 1995; Sholkovitz and Shen, 1995). Moreover, some REEs are frequently used as analogues of long-lived trivalent actinides which contribute considerable radioactivity in high-level nuclear waste disposal (e.g., Curti, 1999; Curti et al., 2005). The REEs usually occur as trivalent ions in natural environment. However, under oxidizing environment such as surface waters, Ce may exist as tetravalent ion, whereas Eu may occur as divalent state under reducing conditions.

It has been widely accepted that the major factors which control the trace element partitioning between crystal and liquid are size of the cation site and ionic radius of the substituting element, and an element which has the most suitable size to the site can be accommodated more easily in the crystal (e.g., Onuma et al., 1968). On the partition coefficient versus ionic radius diagram, trace ions of the same charge draw a parabolic curve which shows a maximum of partition coefficients at the ionic radius of the optimum size for the major cation site of the host mineral (e.g., Onuma et al., 1968). The ionic radius of REEs decrease systematically from $\mathrm{La}$ to $\mathrm{Lu}$, and thus the effect of ionic radius can be examined clearly using them. 
The incorporation of REE into calcite should be a heterovalent substitution, and the charge balance requires a compensation mechanism (e.g., Bruno et al., 2007). The charge balanced substitution of $2 \mathrm{Ca}^{2+}=\mathrm{REE}^{3+}+\mathrm{Na}^{+}$were suggested by Zhong and Mucci (1995) and Fernandes et al. (2008). Lakshtanov and Stipp (2004) examined the substitution of two Eu atoms and one vacancy in three $\mathrm{Ca}$ site in calcite. Curti et al. (2005) suggested the coupled substitution, $\mathrm{H}^{+}+\mathrm{Eu}^{3+}=2 \mathrm{Ca}^{2+}$, and incorporation of an Eu oxy-hydroxo species. Withers et al. (2003) suggested mechanisms like bidentate linkage of one carbonate group, or retention of an $\mathrm{OH}^{-} / \mathrm{H}_{2} \mathrm{O}$ from the hydration shell of REE to explain extend X-ray absorption fine structure (EXAFS) data.

There are several experimental studies on REE partitioning between calcite and aqueous solutions as follows. Terakado and Masuda (1988) experimentally determined the apparent partition coefficients of REEs between calcite/aragonite and aqueous solutions at room temperature and pressure using free-drift technique (Kitano et al., 1971). Their $\mathrm{pH}, \mathrm{Ca}$ and REE concentrations varied dramatically with time as the precipitation was proceeded due to release of $\mathrm{CO}_{2}$ gas from the solution. Their apparent REE partition coefficients for calcite ranged from $\sim 2.5$ to $\sim 10$ and the shapes of REE partition coefficient patterns obviously changed depending on the concentration levels of the REEs added to the initial solution. They suggested that such change might reflect the effect of REE complexation in the solution. Zhong and Mucci (1995) reported the experimental REE partition coefficients between calcite and aqueous solution at $25^{\circ} \mathrm{C}$ and $1 \mathrm{~atm}$ by using constant addition technique which can maintain a steady-state environment (i.e., constant saturation and $\mathrm{pH}$ ) (Zhong and Mucci, 1993). Their REE partition coefficients decreased systematically from $10^{3.6}$ for La to $10^{1.9}$ for $\mathrm{Lu}$ at a concentration level of $70 \mathrm{nM}$. They found that the REE partition coefficients were negatively correlated with the solubility products of the REE carbonate minerals, and were not affected by the calcite precipitation rates or the calculated $\mathrm{CO}_{3}{ }^{2-}$ concentration in the solution. Moreover, the REE partition coefficients, especially for light REEs (LREE), were influenced by REE concentration levels of the solution, although the dissolved REE concentrations used in their experiments are considerably high in comparison with those in natural waters. Lakshtanov and Stipp (2004) carried out the Eu partitioning experiment between calcite and aqueous solutions at $25^{\circ} \mathrm{C}, 1 \mathrm{~atm}, \mathrm{pH} 6$ and ionic strength of 0.1 using the $\mathrm{pH}-$ stat technique (Tesoriero and Pankow, 1996). Their Eu partition coefficients range from $10^{2.49}$ to $10^{3.20}$. They concluded that Eu partitioning was not affected by the calcite precipitation rates or $\mathrm{Eu} / \mathrm{Ca}$ concentration ratios. Tanaka et al. (2004) and Tanaka and Kawabe (2006) conducted the experiments of REE partitioning between cal- cite and aqueous solution $\left(\mathrm{CaCl}_{2}+\mathrm{NaCl}\right)$ at $25^{\circ} \mathrm{C}, 1 \mathrm{~atm}$, pH 6.6 and ionic strength of 0.65 using the constant addition technique (Zhong and Mucci, 1993). The REE partition coefficients reported in Tanaka and Kawabe (2006) are rather variable, but the average values of their REE partition coefficients for several runs range from $10^{2.90}$ to $10^{3.46}$.

The previous REE partitioning experiments described above have been conducted under conditions whose $\mathrm{pH}$, REE concentration levels and crystal growth rate were considerably different from those in natural waters. Obviously, in order to apply the REE partition coefficients to the natural materials, the partition coefficients obtained under the conditions similar to those in natural seawater environment are necessary. Moreover, the REE partition coefficients obtained in the previous studies are considerably variable with respect to the absolute values and the REE pattern shape. In the present study, we would like to report the REE partition coefficients between calcite and aqueous solution using the evaporation method (Terakado and Taniguchi, 2006) which can maintain $\mathrm{pH}$, REE concentration level and crystal growth rate similar to those in seawater environments.

\section{EXPERIMENTAL METHODS}

\section{Overview of the calcite synthesis}

The calcite crystals were synthesized by using the "evaporation method" modified after Terakado and Taniguchi (2006). The parent solution (4 litters) was placed in the reaction container made of acrylic resin. The air in the apparatus was circulated through the reaction container, dehumidifier, cooler and heater. The moisture of the inside air was removed by the dehumidifier, resulting in depression of the water level. The level of the parent solution was controlled by combining a supersonic sensor with the peristaltic pump for the supply of $\mathrm{Ca}$ refill solution. This apparatus was almost closed, but $\mathrm{CO}_{2}$ can be exchanged with outside one through small chinks. The solution was mixed by magnetic stirrer, and its temperature was maintained at $25^{\circ} \mathrm{C}$. All of the experiments were conducted in an air-conditioned room.

\section{Solutions and seed crystals}

The parent and the Ca refill solutions were prepared as follows. $\mathrm{NaCl}$ of $99.8 \%$ purity was dissolved in water and stored in a polyethylene tank. Calcium metal (99.99\%) was dissolved in water to form $\mathrm{Ca}(\mathrm{OH})_{2}$ solution. The parent solution (starting solution) was prepared by mixing the $\mathrm{Ca}(\mathrm{OH})_{2}$ and the $\mathrm{NaCl}$ solutions, and was matured for more than two weeks with air-bubbling. Although the $\mathrm{NaCl}$ and the $\mathrm{Ca}$ metal may contain trace amounts of REE, they are mixed with the REEs supplied from the REE composite solution. The mixed REEs were 
used for the experiments and analyzed after the runs. Ionic strength of the parent solution was adjusted to 0.7 . The Ca refill solution was prepared by diluting the $\mathrm{Ca}(\mathrm{OH})_{2}$ solution with distilled water and was matured for more than two weeks with air-bubbling. The $\mathrm{Ca}$ concentration in the refill solution was about $20 \mathrm{ppm}$. The starting and the refill solutions were filtered through a $0.20 \mu \mathrm{m}$ membrane filter before use. The composite REE solutions were prepared by diluting and mixing the individual REE standard solutions sold for trace element analysis use (Wako Inc., Japan).

The seed crystals were synthesized on silica glass plates $(5 \mathrm{~cm} \times 15 \mathrm{~cm})$, which were stood in the reaction container. After sufficient amounts of calcite crystals were formed, the plates were taken out from the container. The crystals were rinsed with pure water several times, then dried in a dry grove box with molecular sieves $3 \mathrm{~A}$. The weight of seed crystals together with a plate was measured on an electric balance in the dry box whose relative humidity was kept below $0.1 \%$ and static electricity was removed by static elimination equipment.

\section{Procedure}

After one or two weeks from the outset of the experiment, addition of the composite REE solution into the parent solution was started at constant rate $(180 \mathrm{cc} / \mathrm{day})$ by a peristaltic pump. Two REE solutions of 100 and 1000 ppt for every REE were used; i.e., Exp-A and Exp-B, respectively. In Exp-A, the plates with seed crystals were placed in the reaction container at the elapsed time of $406 \mathrm{hrs}$, and the plates were exchanged with new ones at the 889 hrs. The crystal formation before the 889 hrs was designated as Run A-1, and the crystal formation during 889 to 1494 hrs was Run A-2 (see Table 1 and Fig. 1). In Exp-B, the plates with seed crystals were placed in the reaction container at $261 \mathrm{hrs}$, and the plates were exchanged with new ones at 677 hrs. Runs B-1 and -2 correspond to the time intervals of 261 to 677 and 677 to $1130 \mathrm{hrs}$, respectively. The crystals deposited on the bottom of the container during the experiments were removed every 3-5 days.

Small aliquots $(20 \mathrm{~mL})$ of the parent solution were sampled to measure $\mathrm{pH}$, alkalinity, $\mathrm{Ca}$ and $\mathrm{Na}$ concentrations occasionally as indicated in Table 1. For measurement of REE concentrations in the parent solution, the solution of $250 \mathrm{~mL}$ was collected four times during each run (Fig. 1). These solutions were filtered through 0.2 $\mu \mathrm{m}$ membrane filter, acidified immediately with $\mathrm{HCl}$ and stored in polyethylene bottles. To compensate the reduced amount of the parent solution due to sampling, the stored starting solution was added to the parent solution.

The collected plates from the parent solution were rinsed with pure water, dried and weighed in the dry box. For $\mathrm{Ca}$ and REE measurements, the crystals on the plate
Table 1. Chemical data of experimental solutions

\begin{tabular}{|c|c|c|c|c|}
\hline Run & $\begin{array}{l}\text { Time } \\
\text { (hour) }\end{array}$ & $\mathrm{pH}$ & $\begin{array}{l}\text { Alkalinity } \\
(\mathrm{meq} / \mathrm{l})\end{array}$ & $\begin{array}{l}\text { Solution } \mathrm{Ca} \\
\quad(\mathrm{ppm})\end{array}$ \\
\hline \multicolumn{5}{|l|}{ Exp-A } \\
\hline & 0 & 8.35 & 2.17 & 43.6 \\
\hline & 21 & 8.36 & 2.65 & 52.2 \\
\hline & 95 & 8.56 & 4.23 & 84.1 \\
\hline & 143 & 8.72 & 5.78 & 106 \\
\hline & 210 & 8.76 & 6.74 & 128 \\
\hline & 269 & 8.48 & 5.91 & 117 \\
\hline & 311 & 8.32 & 4.95 & 100 \\
\hline & 357 & 8.30 & 4.39 & 90.3 \\
\hline \multirow[t]{13}{*}{ Run A-1 } & 406 & 8.61 & 5.07 & 105 \\
\hline & 477 & 8.43 & 5.07 & 107 \\
\hline & 500 & 8.34 & 4.62 & 101 \\
\hline & 553 & 8.68 & 5.49 & 115 \\
\hline & 576 & 8.69 & & \\
\hline & 621 & 8.37 & 4.73 & 103 \\
\hline & 647 & 8.60 & & \\
\hline & 668 & 8.68 & 5.39 & 116 \\
\hline & 690 & 8.52 & 5.01 & 112 \\
\hline & 792 & 8.37 & 3.49 & 80.9 \\
\hline & 818 & 8.61 & 4.45 & 101 \\
\hline & 889 & 8.45 & 3.85 & 89.6 \\
\hline & & $(8.54)$ & $(4.72)$ & (103) \\
\hline \multirow[t]{10}{*}{ Run A-2 } & 889 & 8.45 & 3.85 & 89.6 \\
\hline & 957 & 8.68 & 5.17 & 127 \\
\hline & 1030 & 8.34 & 4.21 & 97.2 \\
\hline & 1124 & 8.34 & 4.09 & 96.0 \\
\hline & 1182 & 8.34 & 4.21 & 100 \\
\hline & 1238 & 8.34 & 3.47 & \\
\hline & 1298 & 8.61 & 4.35 & 110 \\
\hline & 1354 & 8.43 & 3.65 & 94.8 \\
\hline & 1494 & 8.38 & 3.21 & 103 \\
\hline & & $(8.43)$ & $(4.02)$ & (102) \\
\hline \multicolumn{5}{|l|}{ Exp-B } \\
\hline & 0 & 8.42 & 3.01 & 69.7 \\
\hline & 92 & 8.71 & 4.97 & 111 \\
\hline & 194 & 8.41 & 3.91 & 90.1 \\
\hline \multirow[t]{7}{*}{ Run B-1 } & 261 & 8.43 & 3.51 & 78.9 \\
\hline & 308 & 8.61 & 4.39 & 95.9 \\
\hline & 354 & 8.61 & 4.77 & 105 \\
\hline & 426 & 8.43 & 3.97 & 96.1 \\
\hline & 522 & 8.44 & 3.83 & 79.4 \\
\hline & 677 & 8.44 & 3.61 & 73.7 \\
\hline & & (8.49) & $(4.01)$ & (88.2) \\
\hline \multirow[t]{7}{*}{ Run B-2 } & 677 & 8.44 & 3.61 & 73.7 \\
\hline & 812 & 8.48 & 3.45 & 74.3 \\
\hline & 834 & 8.41 & 3.29 & 69.3 \\
\hline & 976 & 8.40 & 3.45 & 75.8 \\
\hline & 1024 & 8.38 & 3.69 & 78.5 \\
\hline & 1130 & 8.24 & 3.21 & 71.9 \\
\hline & & (8.39) & $(3.45)$ & (73.9) \\
\hline
\end{tabular}

Figures in parentheses indicate the average values. 

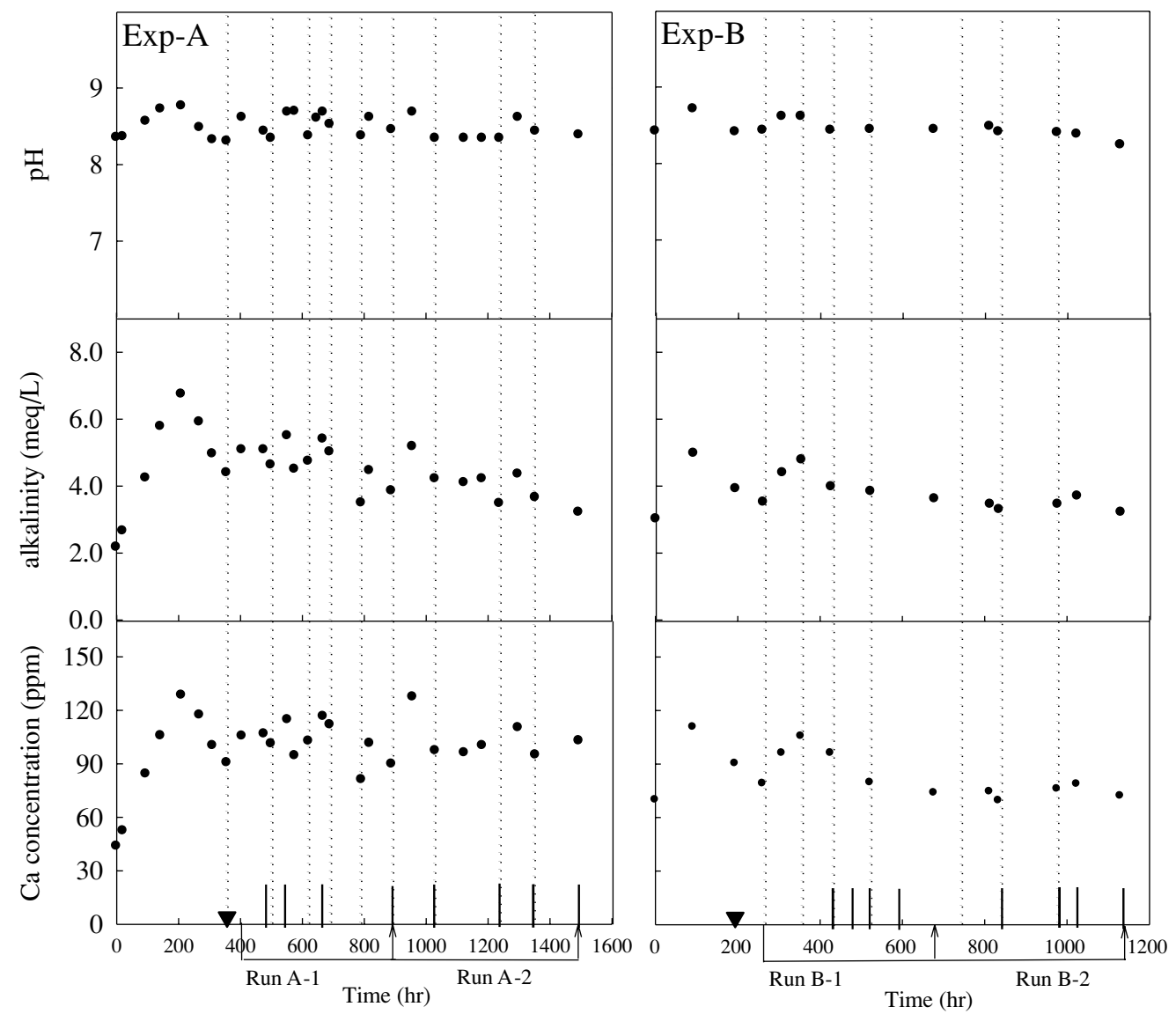

Fig. 1. Variations of $\mathrm{pH}$, alkalinity and Ca concentration in the parent solutions. Reverse triangles on the bottoms show the elapsed times when the additions of the REE solution to the parent solutions were started. Vertical dotted lines indicate the times when the crystals deposited on the bottom of the container were removed. The times of the solution sampling for the REE measurements are indicated by the short vertical solid lines. For Exp-A, the plates with seed crystals were placed in the reaction container at $406 \mathrm{hrs}$ and taken out at $889 \mathrm{hrs}$. At the latter time, the second plates were placed and taken out at $1494 \mathrm{hrs}$. The first and the second plates correspond to Runs A-1 and A-2, respectively. Similarly, in Exp-B, the first plates were inserted at 261 hrs for Run B-1 and exchanged at 677 hrs for Run B-2.

were dissolved in $2 \mathrm{M} \mathrm{HCl}$. For $\mathrm{Na}$ analyses, the crystals separated from the plate were crushed using an agate mortar, rinsed repeatedly with distilled water, and then the crystals were dissolved in $0.04 \mathrm{M} \mathrm{HNO}_{3}$. The solutions were stored in polyethylene bottles.

\section{Analytical methods}

The $\mathrm{pH}$ was measured with a glass electrode $\mathrm{pH}$ meter calibrated with $\mathrm{pH}=7,4$ and 9 standard solutions. Alkalinity was measured by titration with $0.005 \mathrm{~N} \mathrm{H}_{2} \mathrm{SO}_{4}$ to a final $\mathrm{pH}$ value of 4.8. Concentrations of $\mathrm{Na}$ and $\mathrm{Ca}$ were determined by atomic absorption method using $\mathrm{Sr}$ as an interference suppressor on Hitachi Z-8200. Uncertainties in atomic absorption method for $\mathrm{Na}$ and $\mathrm{Ca}$ are usually less than about $2 \%$. REEs were measured by isotope dilution using a thermal ionization mass spectrometer (JEOL05RB). The separation of REEs from major ele- ments was made firstly by coprecipitation with ferrichydroxide (e.g., Masuda and Ikeuchi, 1979). Purification and further separation of light, middle and heavy REEs were performed by conventional cation exchange column method. In order to avoid $\mathrm{Ba}$ interference on La measurements, nitric acid was used for elution (Jahn et al., 1980). Uncertainties in mass spectrometric measurements for most REEs are believed to be less than about 5\%. Total analytical blank (TAB) values for the solution samples were measured three times, and the average values of TAB were subtracted from the measured REE concentrations in the solution samples. As to the crystal sample data, TAB values for the solid samples are considered to be included in the REE concentrations of the seed crystals. The average values of the four measurements of seed crystals were subtracted from the measured REE values for the crystal samples. The errors caused by the TAB on the 
REE concentrations as well as the REE partition coefficients will be discussed later. Powder X-ray diffraction method was applied to the crystals to check crystal forms.

\section{RESULTS}

The major components in the parent solutions

The $\mathrm{pH}$, alkalinity and $\mathrm{Ca}$ concentration in the parent solutions are listed in Table 1. These data are plotted against the elapsed time in Fig. 1. As for Exp-A, the values of $\mathrm{pH}$, alkalinity and $\mathrm{Ca}$ concentration during the initial stage increased from 8.35 to 8.76 , from 2.17 to 6.74 $\mathrm{meq} / \mathrm{L}$ and from 43.6 to $128 \mathrm{ppm}$, respectively. After the maximum values at about $210 \mathrm{hrs}$, these values decreased. Then after $406 \mathrm{hrs}$, relatively stable values were observed, and the average values of $\mathrm{pH}$, alkalinity and $\mathrm{Ca}$ concentration are $8.49,4.37 \mathrm{meq} / \mathrm{L}$ and $103 \mathrm{ppm}$, respectively.

Similarly in the initial stage of Exp-B, pH, alkalinity and $\mathrm{Ca}$ concentration increased from 8.42 to 8.71 , from 3.01 to $4.97 \mathrm{meq} / \mathrm{L}$ and from 69.7 to $111 \mathrm{ppm}$, respectively, and then these values decreased to $8.43,3.51 \mathrm{meq} /$ $\mathrm{L}$ and $78.9 \mathrm{ppm}$, respectively. The average values of the $\mathrm{pH}$, alkalinity and $\mathrm{Ca}$ concentration are shown in Table 1.

The evaporation rates of $\mathrm{H}_{2} \mathrm{O}$ from the parent solution of Exp-A and of Exp-B were 3.3 and $2.8 \mathrm{~kg} / \mathrm{day}$, respectively. The Na concentrations in the solution of ExpA and $-B$ were kept around 15400 ppm $( \pm 540)$ and 15700 ppm $( \pm 310)$, respectively (see Table 2 )

\section{The REE concentrations}

The REE concentration data of the solid and solution samples for Exp-A and -B are listed in Table 2 and are illustrated in Fig. 2. The REE concentration patterns of calcite samples are relatively flat. The calcite samples of Exp-B show similar REE concentrations around $1.6 \mathrm{ppm}$ and are higher than those of Exp-A whose values are around $0.23 \mathrm{ppm}$. It is likely that such difference between Exp-A and-B reflects the difference in the REE amounts added to the solutions. Despite relatively large uncertainties in the Ce concentrations of Exp-A, the REE patterns seem to have negative $\mathrm{Ce}$ anomalies. The estimation on the errors will be described later in Subsection "Error estimation".

All of the REE concentration patterns of the solutions samples show similar shape having slight enrichments of heavy REEs (HREEs) and positive Ce anomalies (Fig. 2). However the REE concentrations of the two solution samples, Runs A-1 and -2, for Exp-A show discrepancy, and similarly those of the two Exp-B samples, Runs B-1 and -2 , are rather different.

\section{Apparent partition coefficients}

The apparent partition coefficient $\left(\mathrm{D}_{\mathrm{Me}}\right)$ of a trace el- 


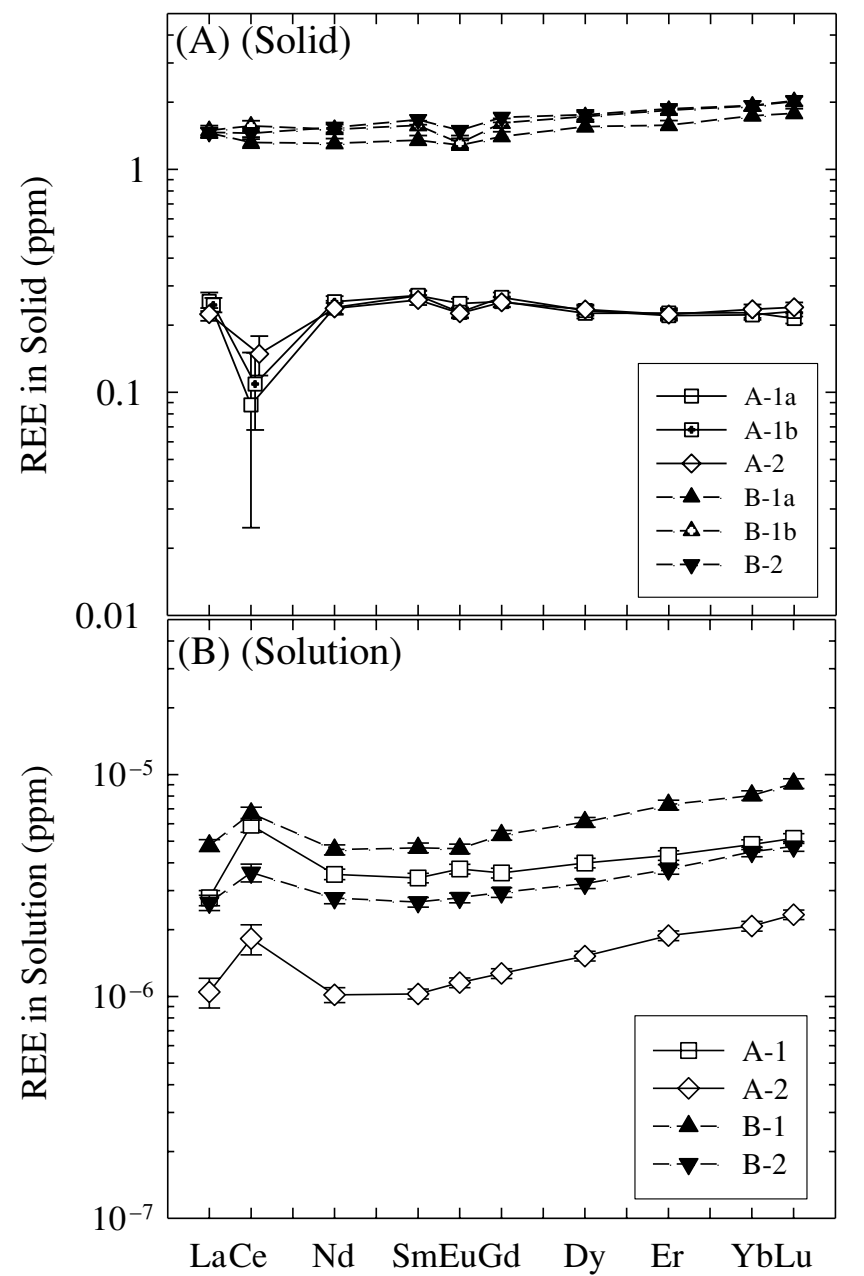

Fig. 2. The REE concentrations in the calcite crystals $(A)$ and the REE concentrations in the parent solutions $(B)$. Vertical bars are intended to show possible errors (see Subsection "Error estimation" for the detail).

ement (Me) between calcite and aqueous solution is defined by the following equation (e.g., Henderson and Kracek, 1927);

$$
\mathrm{D}_{\mathrm{Me}}=\frac{\mathrm{X}_{\mathrm{Me}}}{\mathrm{X}_{\mathrm{Ca}}} \cdot \frac{[\mathrm{Ca}]}{[\mathrm{Me}]}
$$

where $\mathrm{X}_{\mathrm{Me}}$ and $\mathrm{X}_{\mathrm{Ca}}$ indicate the molar fraction of $\mathrm{Me}$ and $\mathrm{Ca}$ in calcite, respectively, and $[\mathrm{Me}]$ and $[\mathrm{Ca}]$ denote molalities of $\mathrm{Me}$ and $\mathrm{Ca}$ in the solution, respectively.

The REE partition coefficients are listed in Table 3 and are illustrated in Fig. 3. These REE partition coefficient patterns show slight LREE enrichment with obvious negative $\mathrm{Ce}$ and slight negative $\mathrm{Eu}$ anomalies. The REE partition coefficients of Run A-2 are about three times higher than those of Run A-1, and similarly, Run

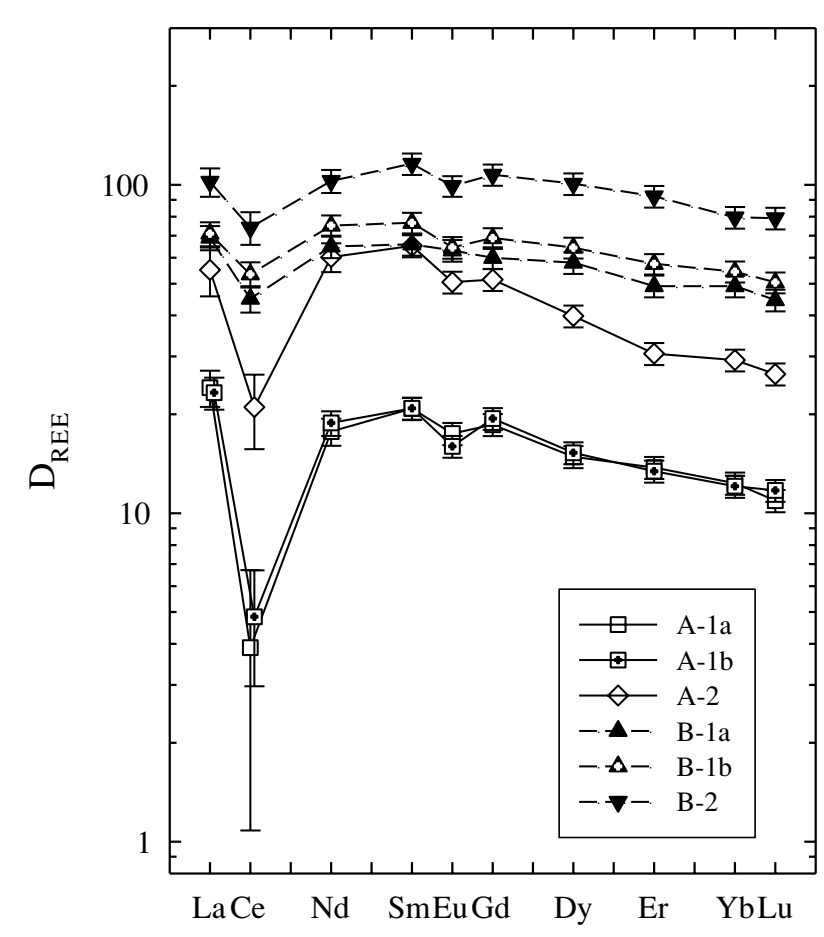

Fig. 3. The apparent REE partition coefficients obtained in this study. Vertical bars are intended to show possible errors (see Subsection "Error estimation" for the detail).

B-2 is somewhat higher than Run B-1. Such difference between Runs B-1 and -2 in REE partition coefficients are considered to be attributed to the difference in the REE concentrations in the parent solutions, because the calcite REE concentrations are similar (cf., Fig. 2). The REE partition coefficients of Exp-B appear to be higher than those of Exp-A.

The REE partition coefficients obtained in the present study are compared to those reported in the previous studies (see Fig. 4). The typical REE partition coefficients reported by Terakado and Masuda (1988) are relatively low and show almost flat REE patterns. The REE partition coefficients for calcite reported by Zhong and Mucci (1995) show large fractionation among REEs decreasing from $10^{3.6}$ for La to $10^{1.9}$ for Lu. The REE partition coefficients for calcite reported by Tanaka and Kawabe (2006) are considerably large ranging from $10^{2.90}$ to $10^{3.46}$. Their REE pattern shows weak convex upward shape having a maximum at middle REE (MREE). The Eu partition coefficients for calcite obtained by Lakshtanov and Stipp (2004) is $10^{2.89}$. Our REE partition coefficients indicate less fractionated REE patterns aside from Ce anomaly. The differences in these partition coefficients shown in Fig. 4 are conspicuous and will be discuss later.

\section{Error estimation}

As seen in Figs. 2 and 3, relatively large error bars are 
Table 3. The apparent partition coefficients of REE and Na

\begin{tabular}{|c|c|c|c|c|c|c|c|}
\hline \multirow{2}{*}{$\begin{array}{l}\text { Run } \\
\text { Plate name }\end{array}$} & \multicolumn{2}{|c|}{ A-1 } & \multirow{2}{*}{$\begin{array}{l}\text { A-2 } \\
\text { A-2 }\end{array}$} & \multicolumn{2}{|c|}{ B-1 } & \multirow{2}{*}{$\begin{array}{l}\text { B-2 } \\
\text { B-2 }\end{array}$} & \multirow[t]{2}{*}{ Recommended values } \\
\hline & A-1a & $A-1 b$ & & B-1a & B-1b & & \\
\hline $\mathrm{La}$ & 24.1 & 23.3 & 55.1 & 69.0 & 71.0 & 102 & 86 \\
\hline $\mathrm{Ce}$ & 3.9 & 4.8 & 21.0 & 45.0 & 53.4 & 74.1 & 62 \\
\hline $\mathrm{Nd}$ & 17.7 & 18.8 & 60.3 & 64.9 & 75.1 & 103 & 86 \\
\hline $\mathrm{Sm}$ & 20.8 & 20.9 & 65.1 & 65.8 & 76.6 & 116 & 94 \\
\hline $\mathrm{Eu}$ & 17.5 & 16.0 & 50.5 & 63.1 & 64.4 & 99.1 & 81 \\
\hline $\mathrm{Gd}$ & 18.6 & 19.4 & 51.4 & 59.9 & 68.8 & 107 & 86 \\
\hline Dy & 14.9 & 15.3 & 39.8 & 57.9 & 64.3 & 101 & 81 \\
\hline $\mathrm{Er}$ & 13.8 & 13.4 & 30.6 & 49.1 & 57.4 & 92.2 & 73 \\
\hline $\mathrm{Yb}$ & 12.3 & 12.1 & 29.2 & 49.1 & 54.4 & 79.5 & 66 \\
\hline $\mathrm{Lu}$ & 10.9 & 11.7 & 26.5 & 44.5 & 50.4 & 79.1 & 63 \\
\hline $\mathrm{Na}$ & $1.29 \times 10^{-5}$ & & $9.81 \times 10^{-6}$ & $1.19 \times 10^{-5}$ & $1.30 \times 10^{-5}$ & $1.38 \times 10^{-5}$ & $1.2 \times 10^{-5 * *}$ \\
\hline
\end{tabular}

*The average of data obtained in Exp-B.

**The average of data obtained in the all runs.

demonstrated in some cases. In Fig. 3, the REE partition coefficients for the different runs show the discrepancies in the absolute values, though their pattern shapes are similar. In this section, we discuss the uncertainty of the values.

For the error estimations on the solid samples (Fig. 2A), the relative uncertainty of $5 \%$ was assigned to all of the REE concentrations as described in Subsection "Analytical methods". In addition to such analytical uncertainty, another factor which contribute to the error is a variation of the REE concentrations in the seed crystals. The REE concentrations in the seed crystals had been measured four times. The errors of the solid samples were calculated including the uncertainties in the seed crystals, but such errors are almost negligible in most cases. However, in some cases such as $\mathrm{La}$ and Ce concentrations, relatively large errors were observed. For example, in Exp-A, the La and Ce concentrations in the seed crystals range from $2.0 \times 10^{-2}$ to $5.0 \times 10^{-2} \mathrm{ppm}$ and from $1.8 \times 10^{-1}$ to $2.7 \times 10^{-1} \mathrm{ppm}$, respectively, whereas the $\mathrm{La}$ and $\mathrm{Ce}$ concentrations in the measured solid samples range from $1.3 \times 10^{-1}$ to $1.5 \times 10^{-1} \mathrm{ppm}$ and $1.7 \times 10^{-1}$ to $1.8 \times 10^{-1} \mathrm{ppm}$, respectively. Thus, the contributions of $\mathrm{La}$ and $\mathrm{Ce}$ concentrations in the seed crystals to the crystal sample values are 10 to $18 \%$ and 50 to $80 \%$, respectively. These values correspond to the errors of 7 to $10 \%$ and 20 to $72 \%$ for the $\mathrm{La}$ and Ce concentrations, respectively. Note that such seed crystal contribution is larger in the lower dopant concentration experiments, i.e., Exp$\mathrm{A}$, and in higher seed crystal concentration cases, i.e., $\mathrm{Ce}$. Thus, considerably large errors are seen in the $\mathrm{Ce}$ case of Exp-A. Moreover, as pointed out in Subsection "Analytical methods", the errors caused by the TAB values for the REE concentrations in the solid samples are included in the errors in the seed crystals.
As for the solution REE data (Fig. 2-B), relatively large errors of about $15 \%$ occur in some $\mathrm{La}$ and Ce values, although most of the errors are about $5 \%$, which reflect the assigned values of the analytical uncertainty. The relatively large errors of $\mathrm{La}$ and $\mathrm{Ce}$ are attributed to relatively large contribution of TAB values. The TAB values for the solution samples were measured three times, and the contributions of the TAB to the $\mathrm{La}$ and Ce concentrations in the solution sample of A-2 are about $12 \%$.

Someone may concern about the effect of the impurity REEs in the $\mathrm{NaCl}$ and the $\mathrm{Ca}$ reagents on the REE concentrations of the parent solutions. However, because the REE concentrations in both solution and solid phases were measured to obtain the REE partition coefficients (Eq. (1)), the REEs originally contained in the $\mathrm{NaCl}$ or the $\mathrm{Ca}$ metal do not affect the partition coefficients.

The error bars of the REE partition coefficients were estimated from the errors of REE and Ca concentrations in the solution and crystal samples. The relative uncertainty of $2 \%$ was assigned to the Ca concentrations. For Exp-A, relatively large errors of 11 to $17 \%$ and 25 to $72 \%$ occur for the La and Ce partition coefficients, respectively, which mainly reflect large errors of the La and Ce concentrations for the solid samples. The errors of the other REE are estimated to be about $8 \%$. As for Exp-B, the errors of about $8 \%$ occur for most of the REE, although relatively large errors of 9 to $10 \%$ and 9 to $11 \%$ are seen for the La and Ce values, respectively.

\section{Crystal growth rate}

The run products obtained in each experiment were checked by XRD and all of the peaks were identified as calcite. Calcite growth rates $\left(R, \mu \mathrm{mol} / \mathrm{m}^{2} / \mathrm{hr}\right)$ on a plate were roughly estimated using the following equation; 


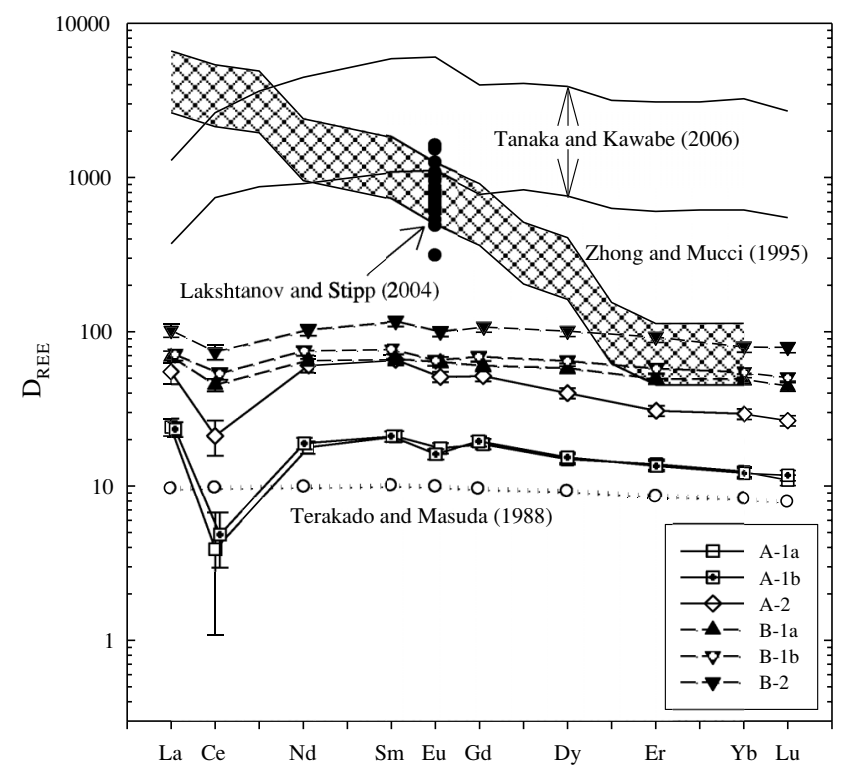

Fig. 4. Comparison among the experimental REE partition coefficients for calcite obtained in the present study and the previous ones (Terakado and Masuda, 1988; Zhong and Mucci, 1995; Lakshtanov and Stipp, 2004; Tanaka and Kawabe, 2006). The symbols of our data are the same as those in Fig. 3. The range of the data reported in Tanaka and Kawabe (2006) are indicated by the maximum and minimum value lines. The shaded area represents the partition coefficients range for the REE concentration of $70 \mathrm{nM}$ reported in Zhong and Mucci (1995). The Filled circles are the data reported in Lakshtanov and Stipp (2004), showing a variation. The open circles with the dotted line are the data of Terakado and Masuda (1988).

$$
R=\frac{V_{\mathrm{f}}-V_{\mathrm{i}}}{S \cdot T}
$$

where $V_{\mathrm{i}}$ and $V_{\mathrm{f}}$ indicate the initial and the final crystal amounts ( $\mu \mathrm{mol})$, respectively, $T$, the run duration (hour), and $S$, the surface area of the seed crystals. Assuming cubic shape for the calcite crystal, the surface area was calculated from the crystal weight and the mean length of the calcite crystals on the plate. The average lengths (i.e., $70 \mu \mathrm{m}$ ) were measured under microscope. The growth rates in the present study are listed in Table 4, together with those in the previous studies. The average growth rate of our study is $880 \mu \mathrm{mol} / \mathrm{m}^{2} / \mathrm{hr}$. The errors in the growth rates mainly reflect the variations of the sizes of the seed crystals.

The degree of calcite saturation indexes $(\Omega)$ were calculated by:

$$
\Omega=\frac{\left[\mathrm{Ca}^{2+}\right] \cdot\left[\mathrm{CO}_{3}^{2-}\right]}{K}
$$

where $K$ is the equilibrium stoichiometric solubility product of calcite, $\left[\mathrm{Ca}^{2+}\right]$ and $\left[\mathrm{CO}_{3}{ }^{2-}\right]$ denote molar concentration in the parent solution. $K$ is $4.39 \times 10^{-7} \mathrm{~mol}^{2} / \mathrm{kg}^{2}$ in 35 per mil salinity seawater at $25^{\circ} \mathrm{C}$ determined by Mucci (1983). The concentration of carbonate ion was calculated by the following equation (Millero, 1979; Zhong and Mucci, 1989):

$$
\left[\mathrm{CO}_{3}^{2-}\right]=\frac{A_{\mathrm{t}}}{10^{-\mathrm{pH}} / K_{2}{ }^{\prime}+2}
$$

where $A_{\mathrm{t}}$ is the titration alkalinity and $K_{2}{ }^{\prime}$ is the second apparent dissolution constants, at $I=0.7$ and $25^{\circ} \mathrm{C}$, reported by Luo and Byrne (2004). The average $\Omega$ values calculated for Exp-A and -B are $2.1( \pm 1.0)$ and $1.3( \pm 0.6)$, respectively.

\section{DISCUSSION}

\section{Partition coefficient versus ionic radius diagram}

It has been generally accepted that ionic radius is an important factor which controls trace element partitioning between solid and liquid. On the partition coefficient versus ionic radius diagram (PC-IR diagram) for the phenocryst-magma pairs, it is generally known that a parabolic curve which shows a maximum of partition coefficients at the ionic radius near the optimum size for major ion site of host mineral can be drawn for trace ions of the same charge (e.g., Onuma et al., 1968; Möller, 1988; Blundy and Wood, 2003). The studies using extend Xray absorption fine structure (EXAFS) spectroscopy by Elzinga et al. (2002) and Withers et al. (2003) showed that the investigated lanthanides occupy a $\mathrm{Ca}$ site in calcite structure. Combining such observation and the above hypothesis, it is expected that the REE partition coefficients for calcite-aqueous solution system demonstrate parabolic shape on the partition coefficient versus ionic radius diagram.

The REE partition coefficients of A-2 and B-2, for examples, are plotted against ionic radius in Fig. 5. These partition coefficient patterns show convex upward shape having vague maximums near LREE. These shapes can be considered as parabolic, but their parabolic curvature is small in comparison with those seen in the phenocrystgroundmass partition coefficient data (cf., Onuma et al., 1968). Such vague parabolic shape suggests that the REE partitioning for calcite is controlled not only by the crystal structure-ionic radius effect but also by other factors such as REE concentrations levels or dissolved REE species suggested by the previous investigators (Terakado and Masuda, 1988; Zhong and Mucci, 1995; Lakshtanov and Stipp, 2004; Tanaka et al., 2004; Curti et al., 2005; Tanaka and Kawabe, 2006). 
Table 4. The growth rates of calcite crystals in this study and previous studies

\begin{tabular}{llccl}
\hline Run & Element & Growth rate $\left(\mu \mathrm{mol} / \mathrm{m}^{2} / \mathrm{hr}\right)$ & Average $\mathrm{D}_{\text {Eu }}$ & Rate dependence \\
\hline This study & & & & \\
A-1 & REE & $500^{(1)} \pm 150$ & $16.7^{(1)}$ & \\
A-2 & REE & $700 \pm 200$ & 50.5 & \\
B-1 & REE & $1300^{(2)} \pm 400$ & $63.7^{(2)}$ & \\
B-2 & REE & $1000 \pm 300$ & 99.1 & \\
& & & & \\
Zhong and Mucci (1995) & REE & $1-20$ & 800 & Uncorrelated \\
Tanaka and Kawabe (2006) & REE & $(30-40)^{(3)}$ & 2884 & \\
Lakshtanov and Stipp (2004) & Eu & $5-650^{(4)}(0.02-2.71 \mathrm{~mol} / \mathrm{mg} / \mathrm{hr})^{(5)}$ & 770 & Uncorrelated \\
& & & & \\
Lorens (1981) & $\mathrm{Co}$ & $12-12000^{(4)}$ & Correlated \\
& $\mathrm{Mn}$ & $12-12000^{(4)}$ & Correlated \\
& $\mathrm{Cd}$ & $130-12000^{(4)}$ & Correlated \\
& $\mathrm{Sr}$ & $240-12000^{(4)}$ & & Correlated \\
& & & & Uncorrelated \\
Mucci and Morse (1983) & $\mathrm{Mg}$ & $50-1040$ & & Uncorrelated \\
& $\mathrm{Sr}$ & $50-1040$ & Uncorrelated \\
& & & Correlated \\
Tesoriero and Pankow (1996) & $\mathrm{Sr}$ & Low $(30-680)^{(4),(6)}$ & Uncorrelated \\
& $\mathrm{Sr}$ & High $(1900-42000)^{(4),(6)}$ & & Correlated \\
& $\mathrm{Ba}$ & Low $(60-650)^{(4),(6)}$ & Uncorrelated \\
& $\mathrm{Ba}$ & High $(1300-27000)^{(4),(6)}$ & & Correlated \\
& $\mathrm{Cd}$ & Low $(1.3-50)^{(4),(6)}$ & &
\end{tabular}

(1) Average values between plate $A-1 a$ and $A-1 b$.

(2) Average values between plate $B-1 a$ and $B-1 b$.

(3) The estimated values are calcurated from the experimental data (0.001 mol/50 hrs for $1 \mathrm{~g}$ seed crystal) in Tanaka and Kawabe (2006) and the assumed surface area $\left(0.52 \mathrm{~m}^{2} / \mathrm{g}\right)$ of reagant calcite.

(4) The values are recalculated in $\mu \mathrm{mol} / \mathrm{m}^{2} / \mathrm{hr}$, origimally reported in $\mathrm{mol} / \mathrm{mg} / \mathrm{hr}$.

(5) Original data reported in Lakshtanov and Stipp (2004).

(6) The original growth rate data were divided into relatively low and high ranges according to the auther's discription.

The partition coefficient patterns in the present study have negative $\mathrm{Ce}$ and Eu anomalies (Figs. 3 and 5). Because our parent solutions are considered to be relatively oxidizing condition due to their exposure to the atmosphere, it is likely that the Ce may exist as $\mathrm{Ce}^{4+}$. It is known that $\mathrm{Ce}^{4+}$ precipitates as highly insoluble $\mathrm{CeO}_{2}$ in seawater (e.g., de Carlo et al., 1998). However, as seen in Fig. 2, the Ce concentrations in our solutions are relatively high in comparison with the neighboring REE concentrations, which is inconsistent with the contention that $\mathrm{Ce}$ had been removed from the solutions as $\mathrm{CeO}_{2}$ precipitate. The valence change from 3 to 4 and the resultant change of ionic radius may explain the $\mathrm{Ce}$ anomalies in the REE partition coefficients patterns. The ionic radii of REEs systematically decrease from $103 \mathrm{pm}$ for $\mathrm{La}^{3+}$ to $86 \mathrm{pm}$ for $\mathrm{Lu}^{3+}$ (Shannon, 1976). The ionic radius of $\mathrm{Ce}^{4+}(87 \mathrm{pm})$ is different from the LREE, but similar to the HREE. The ionic radius of $\mathrm{Ce}^{4+}$ is not suitable for the optimum size of the site of the calcite lattice, and thus the Ce partition coefficient decreases.

It is known that $\mathrm{Eu}$ exist as $\mathrm{Eu}^{2+}$ under reducing environments (e.g., Danielson et al., 1992). The ionic radius of $\mathrm{Eu}^{2+}(117 \mathrm{ppm})$ is larger than that of $\mathrm{Eu}^{3+}(95 \mathrm{ppm})$ and is similar to that of $\mathrm{Sr}^{2+}(118 \mathrm{ppm})$. The known partition coefficient of $\mathrm{Sr}(0.04-0.12)$ for calcite is much lower than those of REEs (Tesoriero and Pankow, 1996). Assuming the similarity of partition coefficients between $\mathrm{Sr}^{2+}$ and $\mathrm{Eu}^{2+}$, the slight negative $\mathrm{Eu}$ anomalies in the partition coefficient patterns can be explained by partial reduction of $\mathrm{Eu}^{3+}$ to $\mathrm{Eu}^{2+}$ in our solutions. However, the mechanism of such Eu reduction under the relatively oxidizing condition is unclear at present.

\section{Influence of crystal growth rate}

It is known that the partition coefficients of the divalent ions (e.g., $\mathrm{Sr}, \mathrm{Mg}, \mathrm{Mn}, \mathrm{Ba}$ and $\mathrm{Co}$ ) are positively or negatively correlated with the calcite growth rate (e.g., Lorens, 1981; Mucci and Morse, 1983; Tesoriero and Pankow, 1996). For example, Tesoriero and Pankow (1996) reported that the partition coefficients of $\mathrm{Sr}, \mathrm{Ba}$ and $\mathrm{Cd}$ for relatively high growth rates were dependent strongly on the growth rates, but almost constant partition coefficients were observed at relatively low growth rates (Table 4). 


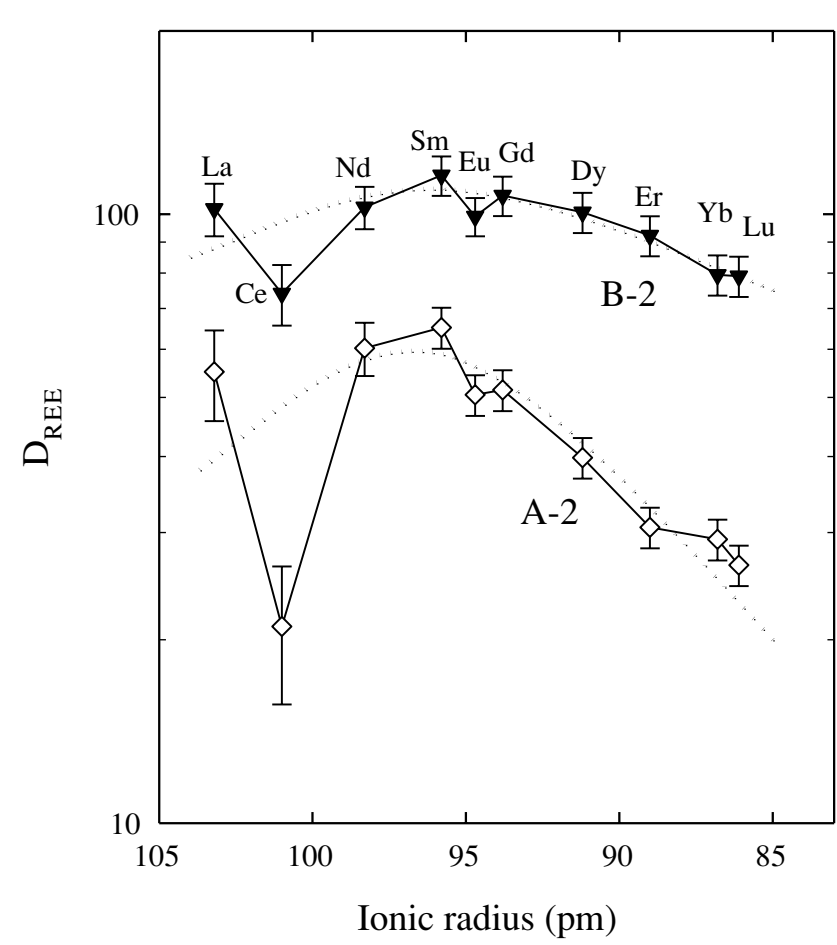

Fig. 5. The partition coefficient-ionic radius diagram (for A-2 and $B-2)$. The ionic radius values $(X$-axis) decrease from left to right. Dotted lines are intended to show possible parabolic curve to fit the data. Ionic radii are 6 coordinate values of Shannon (1976).

Zhong and Mucci (1995) and Lakshtanov and Stipp (2004) pointed out that the REE partition coefficients were independent of the calcite growth rate as far as the growth rate ranges studied were concerned (see Table 4). Wang and Xu (2001) examined the relationship between the adsorption of di- and tri-valent ions on calcite and their partition coefficient for calcite. They pointed out that the effect of calcite growth rate on REE partition coefficients is minimal and hard to observe.

In the present study, the REE partition coefficients of Exp-B were about two to three times higher than those of Exp-A, and the growth rate of Exp-B was about two times higher than that of Exp-A (Table 4). In Exp-B, the partition coefficients of Run B-2 are about 1.5 times higher than those of Run B-1, whereas the growth rate of Run B-2 are about 1.5 times lower than those of Run B-1 (Table 4). In Run A-1, the growth rate of the A-1 a plate ( 450 $\left.\mu \mathrm{mol} / \mathrm{m}^{2} / \mathrm{hr}\right)$ is lower than that of the A- $1 \mathrm{~b}$ plate $(700$ $\mu \mathrm{mol} / \mathrm{m}^{2} / \mathrm{hr}$ ), but their REE partition coefficients are similar (see Table 3 and Fig. 3). Thus, the relationship between the REE partition coefficients and the growth rate is unclear in the present study.

The growth rates of our study (500 to $1300 \mu \mathrm{mol} / \mathrm{m}^{2} /$ hr) are higher than those reported by Zhong and Mucci
(1995) ( 1 to $20 \mu \mathrm{mol} / \mathrm{m}^{2} / \mathrm{hr}$ ), and the REE partition coefficients of these two studies are significantly different (Fig. 4). The growth rates of Zhong and Mucci (1995) and Tanaka and Kawabe (2006) are similar despite the clearly different REE partition coefficients patterns. Although the growth rates of Zhong and Mucci (1995) are about one order of magnitude lower than those reported by Lakshtanov and Stipp (2004) (5 to $650 \mu \mathrm{mol} / \mathrm{m}^{2} / \mathrm{hr}$ ), the Eu partition coefficients of Zhong and Mucci (1995) are similar to those of Lakshtanov and Stipp (2004) (Table 4 and Fig. 4). The growth rates of our study are similar to those of the higher values of Lakshtanov and Stipp (2004), but the Eu partition coefficients of our study are about one order of magnitude lower than those of Lakshtanov and Stipp (2004) (Table 4 and Fig. 4). Therefore, we cannot find any clear relationship between growth rate and REE partition coefficients.

It should be noted that the $\mathrm{CaCO}_{3}$ growth rates of natural materials should be variable according to the situation, and the general values are not known. However, it is interesting to assume the growth rates of 0.1 to $1 \mathrm{~mm} /$ month, which corresponds to 3800 to $38000 \mu \mathrm{mol} / \mathrm{m}^{2} / \mathrm{hr}$. These values are somewhat higher than those of our study, and two to three orders of magnitude higher than those of Zhong and Mucci (1995). Although there is no guarantee that the assumed rates above are always valid as natural values, there are some cases that the higher growth rates are applicable. Thus, the REE partitioning experiments under the higher calcite growth rates would be important.

\section{Influence of REE concentrations}

Terakado and Masuda (1988) indicated that the REE patterns of the partition coefficients obviously changed depending on the REE concentration levels in the initial solutions (e.g., La; 12 to $420 \mathrm{nmol} / \mathrm{L}$ ). Zhong and Mucci (1995) found that the La partition coefficients increased from $10^{2.4}$ to $10^{3.7}$ with increasing REE concentrations from 10 to $70 \mathrm{nmol} / \mathrm{L}$ in the reacting solutions, although this relationship was less obvious for the HREE partition coefficients. They pointed out that such concentration dependence of LREE partition coefficients can be explained by a two-step REE coprecipitation model, though the details were not described.

Tanaka et al. (2004) showed that the partition coefficients of $\mathrm{La}, \mathrm{Ce}$ and Pr using lower REE concentration solutions (e.g., $1 \mathrm{ppb}$ ) are smaller than those of the higher REE concentrations (10 to $100 \mathrm{ppb}$ ), but HREE partition coefficients for low and high concentration cases are similar. They pointed out that these observations might be related to the difference between light and heavy REE in the syntheses of crystalline REE carbonates reported in Nagashima et al. (1973) using $\mathrm{REECl}_{3}$ and $\mathrm{NaHCO}_{3}$ (or $\left.\mathrm{Na}_{2} \mathrm{CO}_{3}\right)$ solutions. In their results, $\mathrm{REE}_{2}\left(\mathrm{CO}_{3}\right)_{3} \bullet 8 \mathrm{H}_{2} \mathrm{O}$ 
precipitated in the $\mathrm{La}$ and $\mathrm{Ce}$ solutions, whereas $\mathrm{NaREE}\left(\mathrm{CO}_{3}\right)_{2} \bullet n \mathrm{H}_{2} \mathrm{O}$ precipitated only in Nd, Gd and Dy solutions.

In the present study, the REE partition coefficients of the higher REE concentration experiment (i.e., Exp-B) are higher than those of the lower REE concentration experiments (i.e., Exp-A). The results of the present study, together with the previous studies mentioned above, suggest that the REE concentration level has an influence on the REE partition coefficients. However, at present it is difficult to draw a definite conclusion, because our REE partition coefficients are rather variable.

\section{Influence of REE species}

It is considered that the different proportions of REE species in the solutions may affect the apparent REE partition coefficients. For example, Tanaka et al. (2004) pointed out that the discrepancy between their REE partition coefficients and those of Zhong and Mucci (1995) is possibly caused by the difference in dominant REE species in both experimental solutions. We have examined the REE species in our parent solution according to Tanaka et al. (2004). They calculated the prorated partition coefficients for the particular REE species such as $\mathrm{REECO}_{3}{ }^{+}$by using the fractions of dissolved REE species obtained by the speciation calculations for the parent solutions.

In the present study, the fractions of REE species were calculated as described below. The REE species of free $\mathrm{REE}$ ions and complex ions of $\mathrm{REECO}_{3}{ }^{+}, \mathrm{REE}\left(\mathrm{CO}_{3}\right)_{2}{ }^{-}$, $\mathrm{REEHCO}_{3}{ }^{2+}, \mathrm{REEOH}^{2+}$ and $\mathrm{REECl}^{2+}$ were assumed. These complex ions are expressed by the following equation;

$$
\mathrm{REE}^{3+}+n A^{v-}=\operatorname{REE} A_{n}^{3-v n}
$$

where $A, n$ and $v$ indicate an anion, a stoichiometric coefficient for $A$ and the valence of $A$, respectively. The complex formation constant is generally defined by activities, but we used the complex formation constants based on molal concentration obtained experimentally at $I=0.7$ and $25^{\circ} \mathrm{C}$ by Liu and Byrne (1998), Klungness and Byrne (2000), Schijf and Byrne (2004) and Luo and Byrne (2007). The complex formation constant $\left(K_{A, n}\right)$ for the chemical reaction formula (Eq. (5)) is expressed by the following equation;

$$
K_{A, n}=\frac{\left[\operatorname{REE} A_{n}^{3-v n}\right]}{\left[\mathrm{REE}^{3+}\right] \cdot\left[A^{v-}\right]^{n}}
$$

where $\left[\operatorname{REE}^{3+}\right],\left[\operatorname{REE} A_{n}{ }^{3-v n}\right]$ and $\left[A^{v-}\right]$ denote molal concentrations of $\mathrm{REE}^{3+}, \operatorname{REE} A_{n}{ }^{3-v n}$ and $A^{v-}$, respectively.
The total REE concentration ([REE $]_{\text {total }}$ ) is written as follows:

$$
\begin{aligned}
{[\mathrm{REE}]_{\text {total }}=} & {\left[\mathrm{REE}^{3+}\right]+\left[\mathrm{REECO}_{3}^{+}\right]+\left[\mathrm{REE}\left(\mathrm{CO}_{3}\right)_{2}^{-}\right] } \\
& +\left[\mathrm{REEHCO}_{3}^{2+}\right]+\left[\mathrm{REEOH}^{2+}\right]+\left[\mathrm{REECl}^{2+}\right] \\
= & \left\{1+\sum_{A} \sum_{n} K_{A, n} \cdot\left[A^{v-}\right]^{n}\right\} \cdot\left[\mathrm{REE}^{3+}\right] \\
= & (1+\theta) \cdot\left[\mathrm{REE}^{3+}\right] .
\end{aligned}
$$

The fraction of a REE complex ([REE $\left.\left.A_{n}{ }^{3-v n}\right]\right)$ to total REE concentration is;

$$
\frac{\left[\operatorname{REE} A_{n}^{3-v n}\right]}{[\mathrm{REE}]_{\text {total }}}=\frac{K_{A, n} \cdot\left[A^{v-}\right]^{n}}{(1+\theta)} .
$$

The concentration of carbonate ion was calculated by Eq. (4). We made speciation calculation for Run A-1 using for $\mathrm{pH}$ and alkalinity values of 8.50 and $4.72 \mathrm{meq} / \mathrm{L}$, respectively.

The results of the speciation calculation using Eq. (8) are shown in Fig. 6. Similarly, the fractions of REE species in the parent solutions used by Tanaka and Kawabe (2006) and Zhong and Mucci (1995) were calculated for comparison. The $\left[\mathrm{HCO}_{3}{ }^{-}\right],\left[\mathrm{CO}_{3}{ }^{2-}\right]$ and $\left[\mathrm{Cl}^{-}\right]$values for the case of Tanaka and Kawabe (2006) were calculated using the average activities reported by Tanaka et al. (2004), the activity coefficients calculated according to Millero and Schreiber (1982), and pH of 6.50 in Tanaka and Kawabe (2006). As for the case of Zhong and Mucci (1995), their average values of $\left[\mathrm{HCO}_{3}{ }^{-}\right],\left[\mathrm{CO}_{3}{ }^{2-}\right]$ and $\mathrm{pH}$ (i.e., 7.5) and $\left[\mathrm{SO}_{4}{ }^{2-}\right]$ and $\left[\mathrm{Cl}^{-}\right]$shown in Kester et al. (1967) were used.

The results of the speciation calculations for the present study and Zhong and Mucci (1995) are similar (Fig. 6). The major REE species for both studies are $\mathrm{REE}\left(\mathrm{CO}_{3}\right)_{2}{ }^{-}$throughout the REE series. However, the dominant REE species of Tanaka and Kawabe (2006) are $\mathrm{REE}^{3+}$ ions.

We have examined the relationships between the REE partition coefficients and the major REE species, but we could not find any regularity. In more detail, the HREE (Er Lu) partition coefficients of our Exp-B are similar to those of Zhong and Mucci (1995) (Fig. 4), which is consistent with the similarity in dominant REE species in both cases (Fig. 6). However, the partition coefficients of light and middle REE (i.e., from La to Dy) of Zhong and Mucci (1995) are different from those of our data, despite similarity in dominant REE species. The REE parti- 


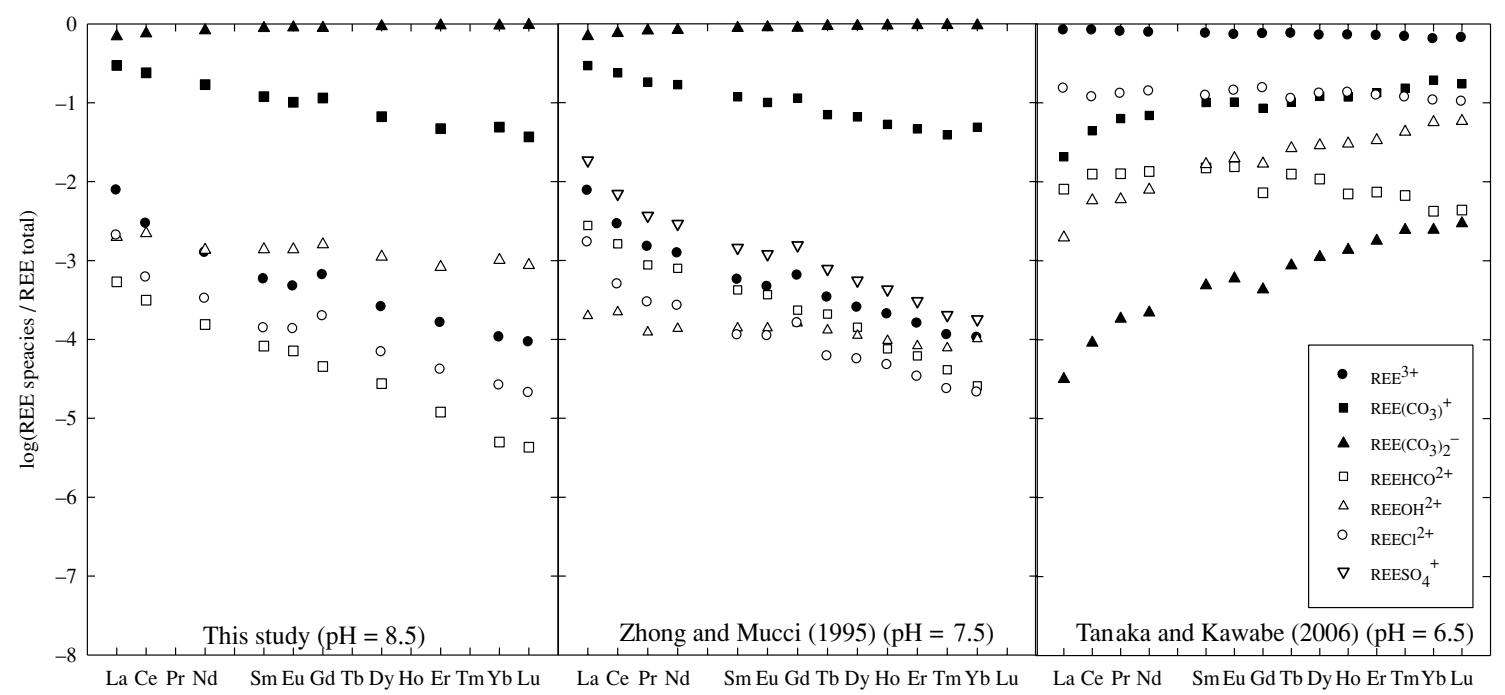

Fig. 6. Results of REE speciation calculations. The ratios of calculated concentrations of each species to the total dissolved REE in the solutions are illustrated (see text for explanation).

tion coefficients of our study are much lower than those of Tanaka and Kawabe (2006), which is consistent with the difference in a major species (i.e., $\mathrm{REE}^{3+}$ is dominant in Tanaka and Kawabe (2006), while $\operatorname{REE}\left(\mathrm{CO}_{3}\right)_{2}{ }^{-}$in the present study). However, the LREE partition coefficients of Tanaka and Kawabe (2006) and Zhong and Mucci (1995) are similar, but their dominant REE species are different (i.e., $\mathrm{REE}^{3+}$ for Tanaka and Kawabe (2006) and $\operatorname{REE}\left(\mathrm{CO}_{3}\right)_{2}{ }^{-}$for Zhong and Mucci (1995)). Thus, we could not draw any clear regularity about the relationship between the dominant REE species and the REE partition coefficients.

Finally, the discussion on the trivalent ion incorporation in divalent sites made by Curti et al. (2005) would be noteworthy in relation to the chemical species in the solutions. Curti et al. (2005) reported that the ternary solid solution model (i.e., $\left.\mathrm{EuH}\left(\mathrm{CO}_{3}\right)_{2}-\mathrm{EuO}(\mathrm{OH})-\mathrm{CaCO}_{3}\right)$, on the basis of the thermodynamic analysis of the Eu partitioning data, was obtained under different $\mathrm{pH}-\mathrm{pCO}_{2}$ conditions. They suggested that the coupled substitution, $\mathrm{H}^{+}$ $+\mathrm{Eu}^{3+}=2 \mathrm{Ca}^{2+}$, prevails at low $\mathrm{pH}$ and high $\mathrm{pCO}_{2}$, possibly following adsorption of Eu-bicarbonate complexes. Moreover in alkaline systems, an Eu oxy-hydroxo group is incorporated preferentially into calcite, reflecting the dominance of the Eu hydroxo species in the solution. They considered two inferred Eu environments in calcite (one with neighboring $\mathrm{CO}_{3}{ }^{2-}$ groups, the other only coordinated by free $\mathrm{O}^{2-} / \mathrm{OH}^{-}$). They suggested that the two different coordination environments of Eu in the calcite lattice could be inherited from adsorption of the dominant $\mathrm{Eu}$ aqueous species at the specific chemical condition of the experiment. However, as discusses in the preceding paragraph, the result of the comparison between the REE partition coefficients and dominant REE species in the parent solutions do not show any influence of the species in the parent solutions. As Curti et al. (2005) concluded, substitution of trivalent for divalent cations in carbonate crystal structures would be a more complex process than the classical isomorphic divalent-divalent substitution.

\section{Significance of the REE partition coefficients obtained in the present study}

As discussed in the previous subsections ("Influence of crystal growth rate" to "Influence of REE species"), the discrepancies of the REE partition coefficients obtained in the previous and the present studies are obvious, and we focused on the differences in some experimental conditions. Among them, the REE concentration level seems to be important. The REE concentration levels in the parent solutions of our study are similar to those in natural seawaters, but those of Zhong and Mucci (1995) and Tanaka and Kawabe (2006) are one to three orders of magnitude higher than those in seawater. Moreover, the REE partition coefficient patterns of Zhong and Mucci (1995) and Tanaka and Kawabe (2006) are significantly different (Fig. 4) despite the similarity of their REE concentrations. The Eu partition coefficients reported by Lakshtanov and Stipp (2004) are about one order of magnitude higher than those of the present study (Exp-B) (Fig. 4), though the REE concentration levels of both cases are similar to those of seawater. Thus, the REE concentration levels cannot be an only reason for the REE partition coefficient differences.

The solution compositions used in the present and the previous studies are considerably different. Zhong and Mucci (1995) used the parent solution including the ma- 
jor seawater ions (e.g., $\mathrm{Mg}^{2+}$ and $\mathrm{SO}_{4}{ }^{2-}$ ) and $\mathrm{Na}_{2} \mathrm{CO}_{3}$ and $\mathrm{NaHCO}_{3}$ were added for $\mathrm{CO}_{3}{ }^{2-}$ sources. Their $\mathrm{pH}$ and ionic strength were 6.76 to 8.32 and 0.7 , respectively. Tanaka and Kawabe (2006) used the $\mathrm{CaCl}_{2}$ and $\mathrm{NaCl}$ solution, having $\mathrm{pH}$ value of 6.6 and ionic strength of 0.65 . Lakshtanov and Stipp (2004) used the $\mathrm{Ca}\left(\mathrm{ClO}_{4}\right)_{2}$ and $\mathrm{NaCO}_{3}$ solution, having $\mathrm{pH}$ and ionic strength around 6 and 0.1, respectively. Terakado and Masuda (1988) used highly oversaturated calcium bicarbonate solution containing $\mathrm{NaCl}$ with ionic strength of 0.1 . Therefore, the differences of the solution compositions are conspicuous and might cause the discrepancies of the REE partition coefficients.

As discussed in Subsection "Influence of crystal growth rate", the relationship between the crystal growth rate and the partition coefficient is unclear, but it should be noted that the estimated crystal growth rates for the previous investigators are much lower than the reasonable values for the natural $\mathrm{CaCO}_{3}$ materials. We considered that although partitioning of trace element between calcite and low temperature aqueous solution is a kinetic process, the experimental results obtained under relatively higher crystal growth rate would be useful for the practical use of the partition coefficients. In this context, our growth rates are closer to the possible natural values than the other growth rates in the previous REE partitioning experiments.

In terms of solution $\mathrm{pH}$, ionic strength, REE concentration level and crystal growth rate, all of these factors in the present study are closer to the natural ones. Some of the factors such as $\mathrm{pH}$ and chemical compositions of Zhong and Mucci (1995) are relatively close to the natural ones, but their REE concentration levels and crystal growth rates are much different from the natural ones. Moreover, the REE concentration levels, $\mathrm{pH}$ and the growth rates of Tanaka and Kawabe (2006) are much different from the natural ones. The ionic strength and $\mathrm{pH}$ of Lakshtanov and Stipp (2004) are rather different from the seawater values. The solution compositions of Terakado and Masuda (1988) varied during the experiments, and their ion strength was lower than that of seawater. The experimental conditions used in the present study are considerably close to these in the seawater environment, and therefore, it can be considered that the REE partition coefficients obtained in the present study would be much plausible for examining REE abundances in natural $\mathrm{CaCO}_{3}$ materials.

\section{Conclusions}

The REE partition coefficients between calcite and aqueous solution were obtained using the evaporation method under the conditions which were relatively close to the natural ones in comparison with those in the previ- ous studies. The REE concentrations in our parent solutions were similar to those of coastal seawater, and the $\mathrm{pH}$ values ranged from 8.2 to 8.7. The experiments were conducted using the low and high REE concentration levels of dopant solutions, and the obtained REE partition coefficients ranged from 10.9 for Lu to 65.2 for Sm and from 44.5 for Lu to 116 for $\mathrm{Sm}$, respectively. These values are one to two orders of magnitude lower than the highest values and about one order higher than the lowest values in the previous studies.

On the partition coefficient versus ionic radius diagram, our partition coefficient patterns show weak convex upward shape having a vague maximum near the LREE, but these curves are not likely to be parabolic as expected from the crystal structure-ionic radius effect which had been shown in the trace element partitioning between phenocryst and groundmass pairs. This suggests that other factors rather than the crystal structure-ionic radius effect should be important for the REE partitioning between calcite and low temperature aqueous solution.

The discrepancies among the experimental REE partition coefficient data obtained in the present and the previous studies may reflect differences in the methods and the experimental conditions. The effects of the growth rate, REE concentration level and REE species in the parent solution were examined, but any clear relationships between these factors and the REE partition coefficients were not found. However, our data as well as the previous ones tend to show dependence on the REE concentration levels in the parent solutions.

Finally, it is surprising that the literature values of the REE partition coefficients between calcite and aqueous solutions are considerably variable ranging over almost three orders of magnitude. In terms of crystal growth rate, ionic strength, $\mathrm{pH}$ and REE concentration level in the parent solution, all of these experimental conditions of the present study are close to natural ones in comparison with those of the previous investigations. As for the practical viewpoint, we believe that our REE partition coefficients would be a plausible data set of the REE partition coefficients between calcite and seawater-like aqueous solutions.

Acknowledgments-This work was supported by JSPS KAKENHI Grant Number 23654174. We thank Professor R. Murray for valuable comments and editorial handling.

\section{REFERENCES}

Alibert, C. and McCulloch, M. T. (1997) Strontium/calcium ratios in modern Porites corals from the Great Barrier Reef as a proxy for sea surface temperature: calibration of the thermometer and monitoring of ENSO. Paleoceanography 12, 345-363. 
Blundy, J. and Wood, B. (2003) Partitioning of trace elements between crystals and melts. Earth Planet. Sci. Lett. 210, 383-397.

Bruno, J., Bosbach, D., Kulik, D. A. and Navrotsky, A. (2007) Chemical thermodynamics of solid solutions of interest in nuclear waste management. OCED Nuclear Energy Agency, Data Bank, 288 pp.

Curti, E. (1999) Coprecipitation of radionuclides with calcite: estimation of partition coefficients based on a review of laboratory investigations and geochemical data. Appl. Geochem. 14, 433-445.

Curti, E., Kulik, D. and Tits, J. (2005) Solid solution of trace $\mathrm{Eu}(\mathrm{III})$ in calcite: thermodynamics evaluation of experimental data over a wide range of $\mathrm{pH}$ and $\mathrm{pCO}_{2}$. Geochim. Cosmochim. Acta 69, 1721-1737.

Danielson, A., Möllar, P. and Dulski, P. (1992) The europium anomalies in banded iron formations and the thermal history of the oceanic crust. Chem. Geol. 97, 89-100.

De Carlo, E. H., Wen, X.-Y. and Irving, M. (1998) The influence of redox reactions on the uptake of dissolved Ce by suspended Fe and Mn oxide particles. Aquat. Geochem. 3, 357-389.

de Villiers, S., Shen, G. T. and Nelson, B. K. (1994) The Sr/Catemperature relationship in coralline aragonite: influence of variability in $(\mathrm{Sr} / \mathrm{Ca})$ seawater and skeletal growth parameters. Geochim. Cosmochim. Acta 58, 197-208.

DeLong, K. L., Flannery, J. A., Maupin, C. R., Poore, R. Z. and Quinn, T. M. (2011) A coral Sr/Ca calibration and replication study of two massive corals from the Gulf of Mexico. Palaeogeogr. Palaeoclimatol. Palaeoecol. 307, 117-128.

Elzinga, E. J., Reeder, R. J., Withers, S. H., Peale, R. E., Mason, R. A., Beck, K. M. and Hess, W. P. (2002) EXAFS study of rare-earth element coordination in calcite. Geochim. Cosmochim. Acta 66, 2875-2885.

Fernandes, M. M., Schmidt, M., Stumpf, T., Walther, C., Bosbach, D., Klenze, R. and Fanghanel, T. (2008) Siteselective time resolved laser fluorescence spectroscopy of $\mathrm{Eu}^{3+}$ in calcite. J. Colloid Interf. Sci. 321, 323-331.

Henderson, L. M. and Kracek, F. C. (1927) The fractional precipitation of barium and radium chromates. J. Amer. Chem. Soc. 49, 739-749.

Henderson, P. (ed.) (1984) Rare Earth Element Geochemistry. Elsevier Science Publishers, 510 pp.

Jahn, B.-M., Bernard-Griffiths, J., Charlot, R., Cornichet, J. and Vidal, F. (1980) Nd and Sr isotopic compositions and REE abundances of cretaceous MORB (Holes 417D and 418A, Legs 51, 52 and 53). Earth Planet. Sci. Lett. 48, 171-184.

Kester, D. R., Duedall, J. W., Connors, D. N. and Pytkowicz, R. M. (1967) Preparation of artificial seawater. Limnol. Oceanogr. 12, 176-179.

Kitano, Y., Kanamori, N. and Oomori, T. (1971) Measurements of distribution coefficients of strontium and barium between carbonate precipitate and solution-Abnormally high values of distribution coefficients measured at early stage of carbonate formation. Geochem. J. 4, 183-206.

Klungness, G. D. and Byrne, R. H. (2000) Comparative hydrolysis behavior of the rare earths and yttrium: the influence of temperature and ionic strength. Polyhedron 19, 99107.
Lakshtanov, L. and Stipp, S. (2004) Experimental study of europium(III) coprecipitation with calcite. Geochim. Cosmochim. Acta 68, 819-827.

LaVigne, M., Hill, T. M., Spero, H. J. and Guilderson, T. P. (2011) Bamboo coral Ba/Ca: calibration of a new deep ocean refractory nutrient proxy. Earth Planet. Sci. Lett. 312, 506515.

Lea, D. W. (1993) Constraints on the alkalinity and circulation of glacial circumpolar deep water from benthic foraminiferal barium. Global Biogeochem. Cycles 7, 695-710.

Liu, X. and Byrne, R. H. (1998) Comprehensive investigation of yttrium and rare earth element complexation by carbonate ions using ICP-MS spectrometry. J. Solut. Chem. 27, 803-815.

Lorens, R. B. (1981) Sr, Cd, Mn and Co distribution coefficients in calcite as a function of calcite precipitation rate. Geochim. Cosmochim. Acta 45, 553-561.

Luo, Y. R. and Byrne, R. H. (2004) Carbonate complexation of yttrium and the rare earth elements in natural waters. Geochim. Cosmochim. Acta 68, 691-699.

Luo, Y. R. and Byrne, R. H. (2007) The influence of ionic strength on yttrium and rare earth element complexation by fluoride ions in $\mathrm{NaClO}_{4}, \mathrm{NaNO}_{3}$ and $\mathrm{NaCl}$ solutions at $25^{\circ} \mathrm{C}$. J. Solut. Chem. 36, 673-689.

Makou, M. C., Oppo, D. W. and Curry, W. B. (2010) South Atlantic intermediate water mass geometry for the last glacial maximum from foraminiferal Cd/Ca. Paleoceanography 25, PA4101, doi:10.1029/2010PA001962.

Masuda, A. and Ikeuchi, Y. (1979) Lanthanide tetrad effect observed in marine environment. Geochem. J. 13, 19-22.

Millero, F. J. (1979) The thermodynamics of the carbonate system in seawater. Geochim. Cosmochim. Acta 43, 1651-1661.

Millero, F. J. and Schreiber, D. R. (1982) Use of the ion pairing model to estimate activity coefficients of the ionic components of natural water. Amer. J. Sci. 282, 1508-1540.

Möller, P. (1988) The dependence of partition coefficients on differences of ionic volumes in crystal-melt systems. Contrib. Mineral. Petrol. 99, 62-69.

Mucci, A. (1983) The solubility of calcite and aragonite in seawater at various salinities, temperatures, and one atmosphere total pressure. Amer. J. Sci. 283, 780-799.

Mucci, A. and Morse, J. W. (1983) The incorporation of $\mathrm{Mg}^{2+}$ and $\mathrm{Sr}^{2+}$ into calcite overgrowths: influences of growth rate and solution composition. Geochim. Cosmochim. Acta 47, 217-233.

Nagashima, K., Wakita, H. and Mochizuki, A. (1973) The synthesis of crystalline rare earth carbonates. Bull. Chem. Soc. Japan 46, 152-156.

Onuma, N., Higuchi, H., Wakita, H. and Nagasawa, H. (1968) Trace element partitioning between two pyroxenes and the host lava. Earth Planet. Sci. Lett. 5, 47-51.

Rickaby, R. E. M. and Elderfield, H. (1999) Plauletonic foraminiferal $\mathrm{Cd} / \mathrm{Ca}$ : Paleonutrients or paleotemperature? Paleoceanography 14, 293-303.

Schijf, J. and Byrne, R. H. (2004) Determination of ${ }_{\mathrm{SO} 4} \beta_{1}$ for yttrium and the rare earth elements at $I=0.66 \mathrm{~m}$ and $t=$ $25^{\circ} \mathrm{C}$-Implications for YREE solution speciation in sulfaterich waters. Geochim. Cosmochim. Acta 68, 2825-2837.

Shannon, R. D. (1976) Revised effective ionic radii and sys- 
tematic studies of interatomic distances in halides and chalcogenides. Acta Crystallogr. 32, 751-767.

Sholkovitz, E. and Shen, G. T. (1995) The incorporation of rare earth elements in modern coral. Geochim. Cosmochim. Acta 59, 2749-2756.

Tanaka, K. and Kawabe, I. (2006) REE abundance in ancient seawater inferred from marine limestone and experimental REE partition coefficients between calcite and aqueous solution. Geochem. J. 40, 425-435.

Tanaka, K., Ohta, A. and Kawabe, I. (2004) Experimental REE partitioning between calcite and aqueous solution at $25^{\circ} \mathrm{C}$ and 1 atm: Constraints on the incorporation of seawater REE into seamount-type limestones. Geochem. J. 38, 19-32.

Taylor, S. R. and McLennan, S. M. (1988) The significance of the rare earths in geochemistry and cosmochemistry. Handbook on the Physics and Chemistry of Rare Earths (Gschneidner, K. A., Jr. and Eyring, L., eds.), 11, 485-578, Elsevier.

Terakado, Y. and Masuda, A. (1988) The coprecipitation of rareearth elements with calcite and aragonite. Chem. Geol. 69, 103-110.

Terakado, Y. and Taniguchi, M. (2006) A new method for the study of trace element partitioning between calcium carbonate and aqueous solution: a test case for $\mathrm{Sr}$ and $\mathrm{Ba}$ in- corporation into calcite. Geochem. J. 40, 161-170.

Tesoriero, A. J. and Pankow, J. F. (1996) Solid solution partitioning of $\mathrm{Sr}^{2+}, \mathrm{Ba}^{2+}$ and $\mathrm{Cd}^{2+}$ to calcite. Geochim. Cosmochim. Acta 60, 1053-1063.

Wang, Y. and Xu, H. (2001) Prediction of trace metal partitioning between minerals and aqueous solutions: a linear free energy correlation approach. Geochim. Cosmochim. Acta 65, 1529-1543.

Withers, S. H., Peale, R. E., Schulte, A. F., Braunstein, G., Beck, K. M., Hess, W. P. and Reeder, R. J. (2003) Broad distribution of crystal-field environments for $\mathrm{Nd}^{3+}$ in calcite. Phys. Chem. Miner. 30, 440-448.

Zhong, S. and Mucci, A. (1989) Calcite and aragonite precipitation from seawater solutions of various salinities: precipitation rates and overgrowth compositions. Chem. Geol. 78, 283-299.

Zhong, S. and Mucci, A. (1993) Calcite precipitation in seawater using a constant addition technique: A new overall reaction kinetic expression. Geochim. Cosmochim. Acta 57, 14091417.

Zhong, S. and Mucci, A. (1995) Partitioning of rare earth elements (REEs) between calcite and seawater solution at $25^{\circ} \mathrm{C}$ and $1 \mathrm{~atm}$, and high dissolved REE concentrations. Geochim. Cosmochim. Acta 59, 443-453. 